
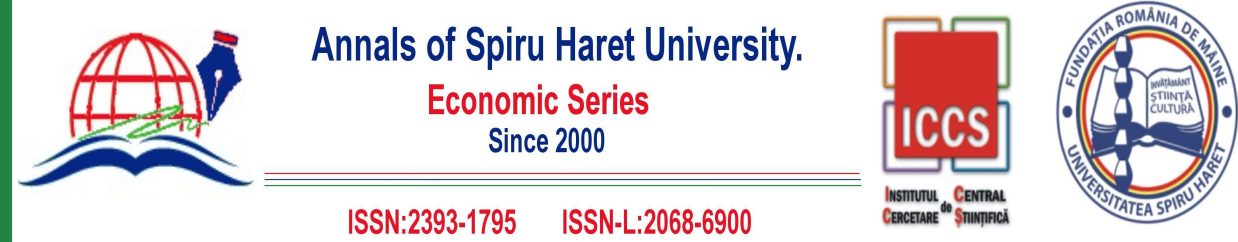

Issue 2/2019

\title{
THE ROLE OF AGRARIAN REFORMS IN THE SOCIO- ECONOMIC DEVELOPMENT OF NAKHCHIVAN AUTONOMOUS REPUBLIC
}

\author{
Sadagat AHMADOVA ${ }^{1}$ \\ ${ }^{1}$ Assoc. prof., Department of The World Economy, Baku State University, \\ Azerbaijan, Tel.: +994125390517, Email: mmndu2010@gmail.com
}

How to cite: AHMADOVA, S. (2018). "The Role of Agrarian Reforms in The Socio-Economic Development of Nakhchivan Autonomous Republic." Annals of Spiru Haret University. Economic Series, 19(2), 153-163, doi: https://doi.org/10.26458/1928

\begin{abstract}
After independence, the article was devoted to carrying out appropriate reforms to ensure the development of agriculture, which is one of the key areas of the economy of the Nakhchivan Autonomous Republic. It was noted that the leadership of the autonomous republic at the same time, and then the country's leadership, was instructed to issue the necessary orders for the development of the agrarian sector and the fulfillment of the tasks arising from these orders. In addition, the role of the agrarian sector in ensuring socio-economic development was justified, and the corresponding statistical indicators are reflected in the article. It has been shown that food security is the key to agrarian reform, which is to restrict imports by stimulating domestic production and, above all, production-driven production.
\end{abstract}

Keywords: agriculture; agrarian reforms; sustainable development; socioeconomic development; food security; domestic production.

JEL Classification: B55

\section{Introduction}

The regulation of economic processes in the Autonomous Republic of Nakhchivan is carried out not only by industry, but also by the dynamic development of agriculture (agrarian sector), which is one of the leading directions and driving 


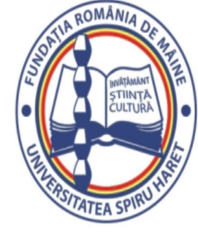

Issue 2/2019

force of social organization. Agriculture is an important area of economic and social development of the Autonomous Republic of Nakhchivan. One of the leading areas of autonomous agriculture, where more than $70 \%$ of the population lives in rural areas, is agriculture.

This policy, established by national leader Heydar Aliyev, is now needed to identify and improve the long-term prospects for agricultural development and the necessary measures in an autonomous republic. Along with this, agriculture is a set of factors listed in the following figure:

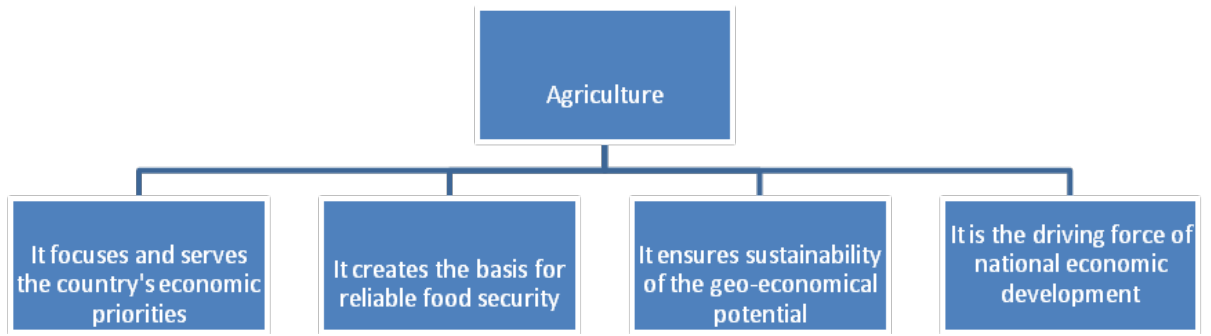

Fig. 1. Agricultural Development Targets in Nakhchivan Autonomous Republic (NAR)

\section{Research Method}

The methods used in this research are conceptual method, used in studying statistical events and phenomena from the past, or the research of a problem's link to the past [Kaptan, 1998], and the review method, a research method which is focusing to describe a situation from the past or the present in agricultural development of NAR. To gather the research data, newspapers, written sources and magazines which belonging to the various time periods related to the study, books were reviewed and analyzed according to statistical data.

1. Agricultural development target as major direction of economic development of Autonomous Republic of Nakhchivan

The development of agriculture in the Autonomous Republic of Nakhchivan also contributes to the development of the non-oil sector of the country. In general, the efficiency of the agricultural sector in our country, its prospects for the distant future, the transformation of socialization policy into a driving force, the expansion of social production and the increase in the level of employment of the population 154 


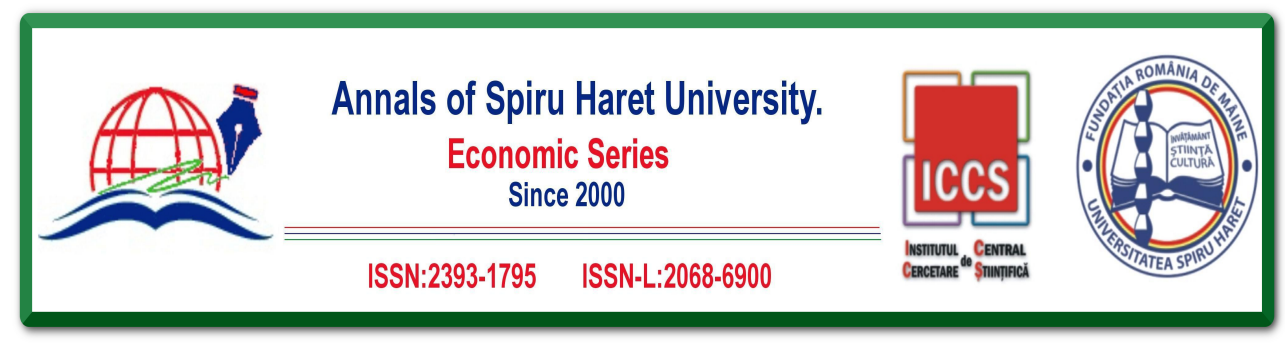

Issue 2/2019

are of great importance. (http://www.fao.org/3/w4760e02.htm) The national leader of our people, Heydar Aliyev, created a solid base for the development of this sphere in our country during the times of the former Soviet Union. In general, we can divide the measures implemented in the Autonomous Republic into three stages that are consistent and promising for socio-economic development:

1. Basic principles that began in 1991-1993;

2. Organizational stages that lasted from 1995 to 2000;

3. Since 2000, it has focused on progress achieved.

These stages were reflected in the sectoral structure of the economy, including agriculture, with its sustainable development. The third stage in the Nakhchivan Autonomous Republic has been developing rapidly over 17 years since 2000 .

In our country, the foundations were laid for a new stage of development for the transformation of agriculture into an economic priority of the state, expansion of the field in macroeconomic indicators (https://www.econstor.eu/bitstream/10419/ 139291/1/v10-i11-a10-BF02929320.pdf) and transformation of a high-yielding region. The village of Heydar Aliyev, who has been elected President of the Republic of Azerbaijan since 1993, laid the foundations for a policy of legal and economic regulation.

It is obvious that in our country, along with all this, the National Program for Agrarian Development was adopted. This program is focused on the international experience of creating new forms of agriculture and relies on the availability of agriculture that meets different conditions. One of them is the United States, the Netherlands, Canada, as well as the history of the Israeli state and other traditional farming methods, such as a shortage of land and water resources and unique management and efficient farming in difficult natural conditions, cob traditions (state farms) and alcoholic beverages (private farms), geographical and at the same time closely related to the national traditions of fraternal Turkey. (https://www.apotokyo.org/00e-books/AG-10_AgrarianReforms.htm)

Based on the above experiments, a number of legal and regulatory acts in our country and in its regions (including the Autonomous Republic) were adopted to effectively regulate agrarian processes. During the years of independence in the field of development of the agrarian sector, a large number of legal regulation tools were used to regulate and correct the processes in this area, ensure substantial results and turn the country into a regional policy. 


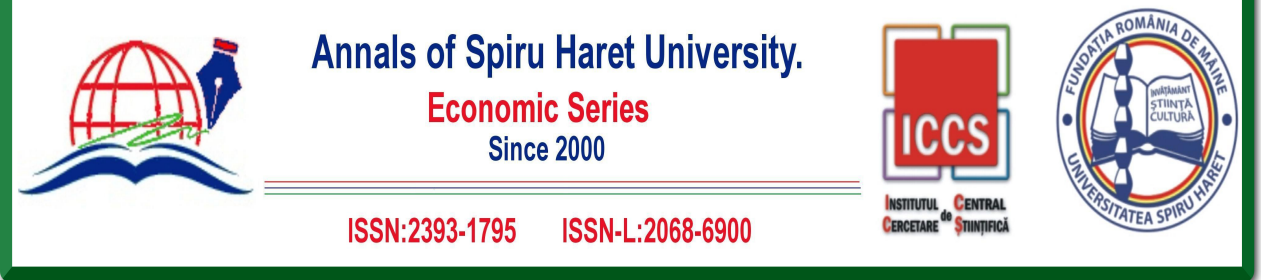

Issue 2/2019

In accordance with the Decree of November 20, 2014 from the Reserve Fund of the President of the Republic of Azerbaijan, provided for in the State Budget of the Republic of Azerbaijan for 2014, Agrolizing Open Joint-Stock Company allocated 8 million manat and is a factor to meet the needs of agricultural producers in agricultural equipment. 10 million manat will be allocated for the sale of livestock and livestock farms with a 50 percent discount on leasing.

On the other hand, in accordance with the Decree of the President of the Republic of Azerbaijan dated August 19, 2015 "On State Support for Animal Breeding", further improvement of the living conditions of the population, an increase in the number of animals with high productive genetic potential as to be seen. For pet owners, a subsidy of 100 (one hundred) manat for each cataclysm process resulting from artificial insemination in order to increase interest in this area.

Apparently, all this was an integral part of the urgent measures taken to solve the agrarian problems in our country, as well as the basis of agrarian relations.

Regardless of the degree of economic entities, it is important to emphasize the role of agriculture in macroeconomic processes, which is important for regulating socio-economic processes that have always been the dominant part of economic relations, it is important to note the importance of agrarian relations, such as a mechanism guaranteeing the indivisibility of peasant-soil relations. Agrarian relations are relations with land and land use. [Valiyev, 1999]

The political dexterity of the national leader of our country, Heydar Aliyev, and his worthy management skills made the agricultural sector even more important for the development of the national economy of our country and laid the foundations of the economic and production relations that will be necessary in the new economic conditions. All these or other aspects are the most important expression of its economic and legal regulation, as is the case in our country, constantly increasing the economic potential of the Nakhchivan Autonomous Republic.

The fact that the great leader Heydar Aliyev was still in the country as a whole was the fact that the land reform initiated by the Governor of the Nakhchivan Autonomous Republic in the Soviet and Gal villages of the Julfa region became a reality. This economic policy has become an excellent example for each of the CIS countries. Reforms were very important. It should be noted that in 1994 only eight meetings were held to address the problems of agriculture and reforms in the agricultural sector. On December 9 and 10 of this year, in the Supreme Council of the 156 


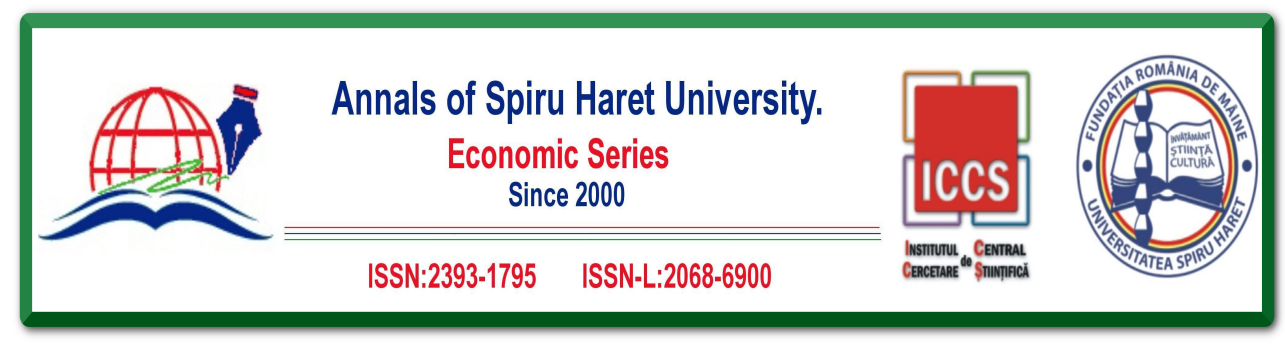

Issue 2/2019

Republic of Azerbaijan, with the participation of delegations from Turkey, China, Israel, Iran, Russia and other countries, an international conference entitled "Agrarian Transformation: Problems and Solutions" was held. (https://www.economist.com/ asia/2017/10/12/for-asia-the-path-to-prosperity-starts-with-land-reform) The conference was aimed at ensuring the effectiveness of agrarian reforms and the use of international experience in this field. In 1994, on the orders of Heydar Aliyev, experiments were conducted in the Zagatala and Khiza regions of Azerbaijan, and some results were achieved. Here I would like to note that the political activity of the national leader during the Nakhchivan Autonomous Republic was carried out in the Azerbaijan state farm in the Julfa region, and the goal was also achieved.

Agrarian reforms in market conditions:

1) to keep the economy open for market relations in accordance with the requirements of the modern era;

2) further increase the role of factors of productivity, quality and competitiveness at the macroeconomic level;

3) to ensure the transition of the agricultural sector to a flexible business environment;

4) increase the mechanical economic value;

5) play the most important mechanism for improving the social status of the population, etc., in terms of its content.

In the modern economic system, the basic legality of the agrarian sector is undoubtedly the creation and development of subjects based on multiculturalism. Because market relations, as proponents of property, reflect issues of regulation and promotion of relations in this area. In this sense, it is very important for the creation and successful functioning of business entities that are necessary for modern economic conditions. Therefore, the creation of peasant farms, which created the driving force of economic activity, was among the most pressing issues.

As a result of targeted measures taken in the field of state regulation of the economy, the development of the sectoral structure of an autonomous republican economy was ensured. The created healthy economic environment has become the driving force of economic and social development. It is a fact that at all times the consumer is the basis of the economy, and man is the guarantor of the continuity of production. In this context, multifaceted activities contribute to the economic interests of the human factor as producers, consumers, hard-working peasants. The protection and development of state-peasant and land relations have always been 


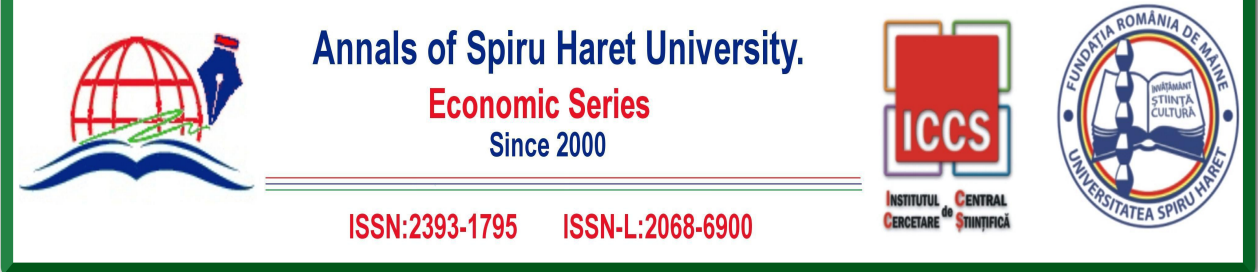

Issue 2/2019

the focus of attention of the Nakhchivan Autonomous Republic with the goal of organizing and managing agricultural activities in leading sectors of the economy. There is a need to provide financial support to rural residents, ensuring the availability of technological equipment at the modern level, or, more precisely, with comprehensive care for residents in the framework of the regulatory policy of the state. The most optimal solution of all these or other issues is the Decree signed by the Chairman of the Supreme Assembly of the Nakhchivan Autonomous Republic on January 28, 2005, "On additional measures to expand leasing in the agrarian division in the Nakhchivan Autonomous Republic", therefore we need to accelerate its implementation and promote the application of the ECT results in production (innovative development).

Based on this historical and legal document, the basis of the economy begins with production. Therefore, the manufacturer must improve its supply with the necessary agricultural equipment, produce high-quality products and ensure its time and quality losses. [Braverman, \& Guasch, 1990] All this once again shows that the economy of the Autonomous Republic was focused on the correct solution of agrarian issues.

According to the above-mentioned factors, the main research question is the issue of agricultural development, which is the relationship between land ownership and the ownership of the means of production for agriculture, land ownership and its use. [Valiyev, \& Gafarov, 2004]

These economic and legal mechanisms have become an important regulatory tool for ensuring the intensive development of agriculture in the autonomous republic. It became possible to expand the scope of production, sustainable development of the agricultural sector and increase productivity.

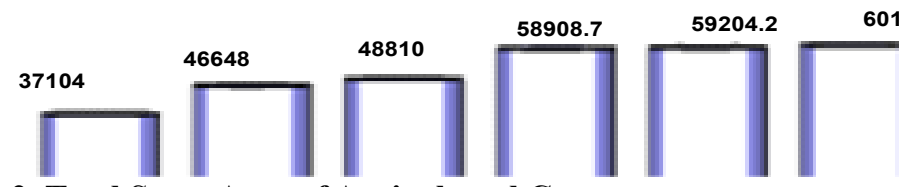

Fig. 2. Total Sown Area of Agricultural Crops in Nakhchivan Autonomous Republic (ha)

Source: Prepared by the author based on http://statistika.nmr.az/source/agriculture/index.php 
Issue 2/2019

When we look at the picture, we see the total area of crops in the Autonomous Republic in different years. As it can be seen, the expansion of production capacities in the agricultural sector of the Autonomous Republic, as well as decrees and orders signed by both the head of state and the chairman of the Supreme Assembly of the Autonomous Republic as a result of the state programs, strategies and other legal acts approved by them, became possible thanks to decisive measures. In particular, the launch of regional development programs since 2003, the acceleration of the legal regulation of agrolizing and potatoes since 2005, the launch of a new phase of food security since 2008 and the development of fruits and vegetables in 2012 and 2016. The adoption of five-year government programs of the same name contributed to the consistent and dynamic development of the relevant areas.

Naturally, the main goal is to constantly maintain the demand of the population and increase the productivity of the agricultural sector. In this regard, it is important to increase attention to the expansion of crop fields in the quality of agricultural products. As shown in Fig. 2, crops were planted on 6.1311 ha in the Autonomous Republic for harvesting in 2017.

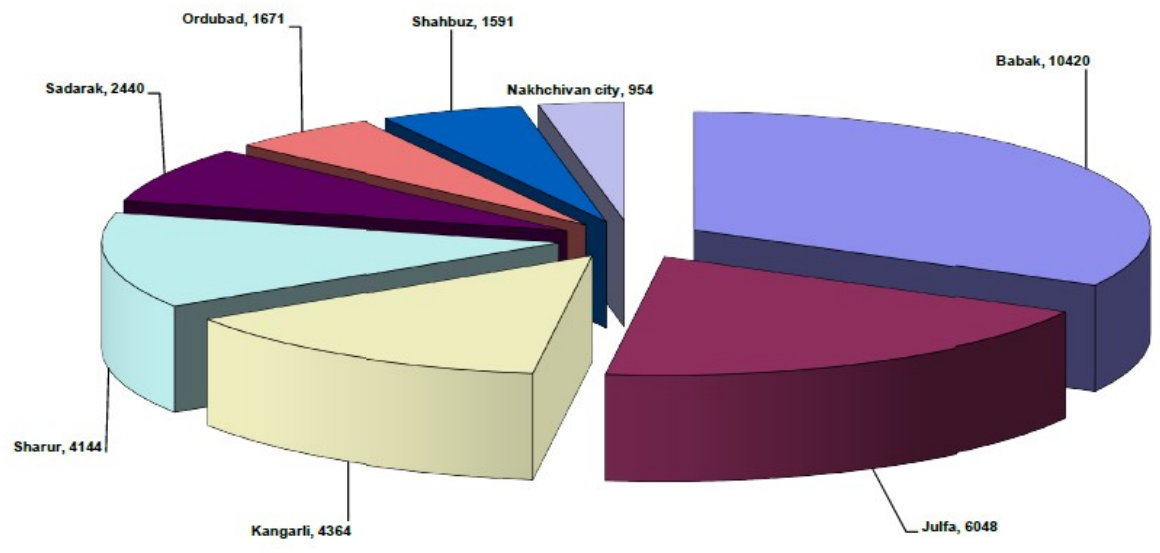

Fig. 3. Information on the Sowing Area (ha)

The picture was prepared by the author on the basis of statistical information. It should be noted that 31,632 hectares of this indicator was formed as a result of a determined approach to the production of demanded products. Grain planting areas 
Issue 2/2019

are 22,268 hectares of wheat and 9,364 hectares of barley. When applying for statistical information for the reference period, we encounter the following information about grain cultivation in the autonomous republic:

In the current Autonomous Republic, which is committed to the historical tradition of its territory due to the specialization of its territory, population settling, productivity indicators, the issues of planting, cultivating and supplying were seriously considered. Issues related to the provision of food security throughout the year, production of demand-oriented products, and, most importantly, stimulation of local production have become the main prerequisites of the autonomous republic. On this basis, 93,419 tons of crops have been harvested from grain crops this year, which is 19,000-50 tons more than the harvest in 2007.

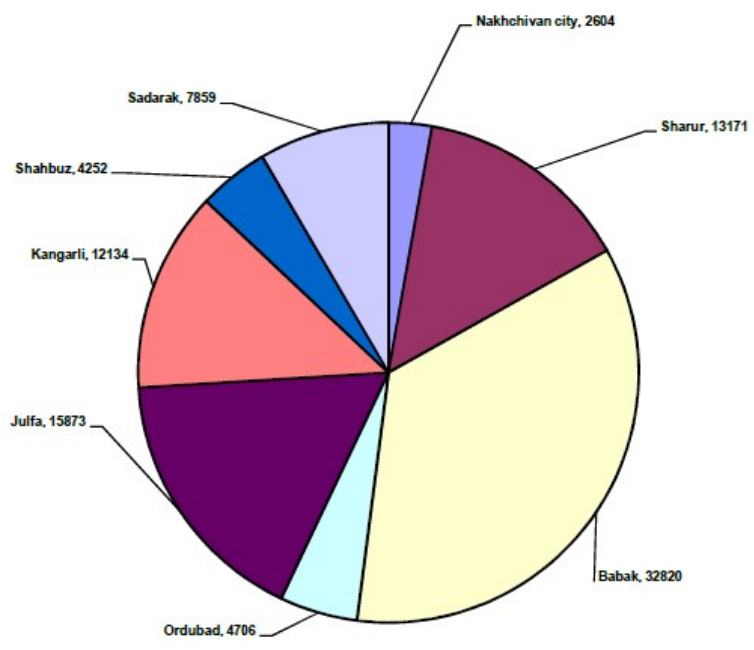

Fig. 4. Quantity of Grain Produced in 2008 in Nakhchivan Autonomous Republic (Tons)

The picture was prepared by the author on the basis of statistical information.

As already mentioned, on January 28, 2005, the Chairman of the Supreme Assembly of the Nakhchivan Autonomous Republic signed a decree "On additional measures to expand leasing in the agrarian division in the Nakhchivan Autonomous Republic". He supported the contribution of the agricultural sector to production 

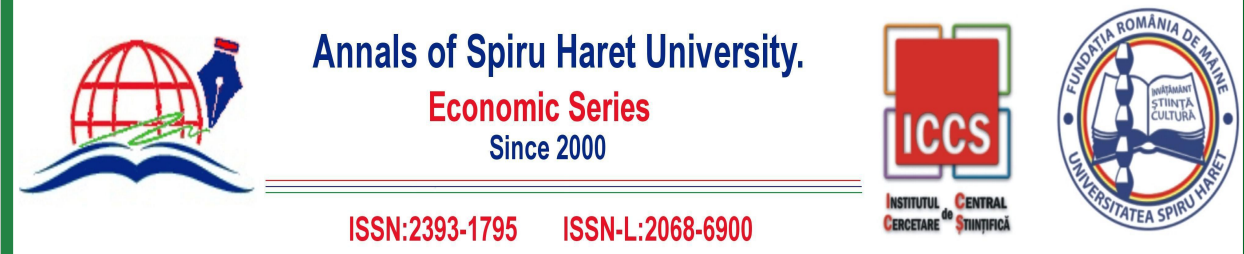

Issue 2/2019

relations, expanded its usefulness and created a solid base in the field of providing landowners with machinery and equipment. These issues, which became a decisive factor in ensuring agricultural, economic activity and food security, led to the achievement of productive indicators in the agricultural sector of the autonomous republic and its specialized areas. Open Joint-Stock Company "Nakhchivan Agroleasing", established in 2005 by order of the Republic of Azerbaijan, promoted the use of the necessary machinery and equipment for agricultural producers. The introduction of technology in the Autonomous Republics has already become a tradition in various names and purposes, which gives users an incentive to produce products.

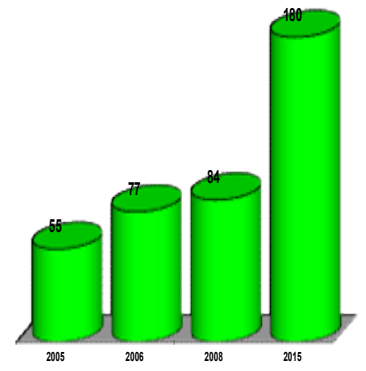

Fig. 5. Information on the Number of Agricultural Machinery Imported to Nakhchivan Autonomous Republic in Different Years (Numbers)

The picture was prepared by the authors based on statistical information.

In addition, it can be noted that this process was continued in 2016, agricultural producers were provided with the necessary equipment, 66 different agricultural machines and process equipment were delivered to Nakhchivan Agroleasing JointStock Company, rented by landowners. It should be noted that this figure was 1,478 for the first half of 2017 and amounted to 1,978 units. In January-July 2017, 175 units of agricultural machinery and equipment were delivered to manufacturers through leasing, and 7 units were sold in cash. 


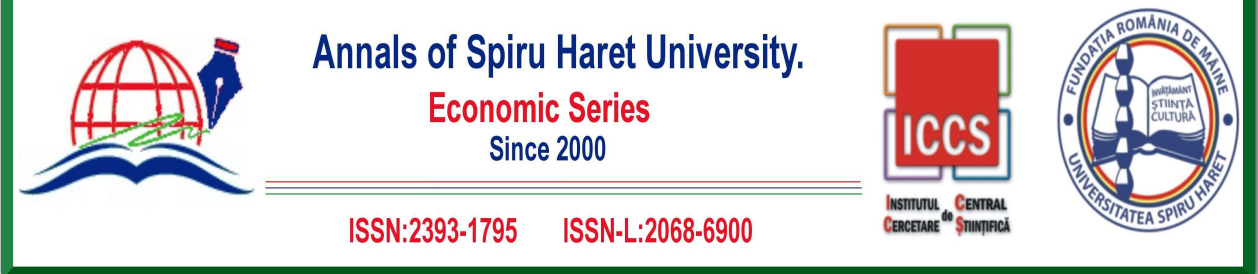

Issue 2/2019

\section{Conclusion}

Important steps to solve the problems we deal with are still of great importance for the political activities of the national leader. Because, of course, there are a number of mechanisms that are needed to stimulate production, which can be expressed in improving economic, technical and financial support. The only successful solutioning of these issues is directly related to the name and political activities of the national leader. Thus, Azerbaijani-Japanese cooperation, founded during the visit of Heydar Aliyev to Japan in 1998, created a fruitful basis for effective economic cooperation, as well as in the political sphere. In accordance with the Memorandum of Understanding signed with the Government of Japan, in 1998-2011, farmers purchased and used 863 agricultural equipments, including 297 units of combine harvesters, 212 tractors and other equipment and accessories. 753 units of equipment, including 130 combine harvesters and 104 tractors were purchased and put into operation in the partner fund. [Abasov, 2013] They were designed for future prospects of the agricultural sector, becoming an effective expression of independence and international economic relations.

Apparently, regardless of the form of economic formations, the main task is to organize targeted actions aimed at solving the main problems of the economy and ensuring access to the appropriate direction. Therefore, it is necessary to study the problems of the population, increase its employment level, increase the industry's share in the state's economic programs, organize the sectoral structure of the economy, and so on.

Of course, all these are important indicators characterizing the efficient use of labor resources, the correct distribution of their production areas and their development as a productive force. At the same time, these processes are problems that lead to the organization and development of the agrarian infrastructure.

\section{References}

[1] Abasov, I. D. Agriculture of Azerbaijan and World Countries. Baku: East-West, 2013, $712 \mathrm{p}$.

[2] Garibov, A. H. International Economic Relations and Customs Business (A Brief Explanation of Terms). Baku: Sada, 2007, 112 p.

[3] Nakhchivan Encyclopedia. In two volumes. I vol. Nakhchivan: 2005, 361 p.

[4] 75th jubilee-statistical bulletin of Nakhchivan Autonomous Republic. Nakhchivan: $1999,96 \mathrm{p}$. 


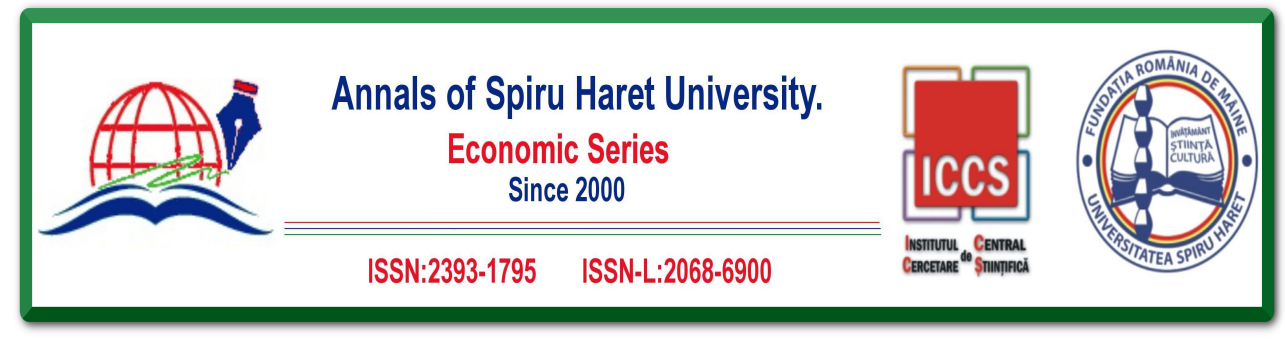

Issue 2/2019

[5] Valiyev, T. S., Babayev A., P. Economic theory. Baku: Çashıglu, 1999, 684 p.

[6] Valiyev, T. S., \& Gafarov, Sh. Economic theory. Baku: Azpoliqraf LTD LTD, 2004, 504 p.

[7] Avishay, Braverman \& J. Luis Guasch. "Agricultural Reform in Developing Countries: Reflections for Eastern Europe." American Journal of Agricultural Economics, Vol. 72, No. 5, Proceedings Issue (Dec., 1990), pp. 1243-1251

[8] Kaptan, S. Bilimsel Araştırma ve İstatistik Teknikleri. Tekışık Web Ofset, 1998.

[9] http://www.fao.org/3/w4760e02.htm

[10] https://www.econstor.eu/bitstream/10419/139291/1/v10-i11-a10-BF02929320.pdf

[11] http://www.amauta.info/files/agrarianreforms.pdf

[12] https://www.apo-tokyo.org/00e-books/AG-10_AgrarianReforms.htm

[13] https://www.economist.com/asia/2017/10/12/for-asia-the-path-to-prosperity-startswith-land-reform 



\section{BACHELOR, MASTERAL AND DOCTORAL PAPERS}


